\title{
LEUKOPLAKIA OF THE KIDNEY PELVIS
}

\author{
HERMAN L. KRETSCHMER, M.D. \\ CHICAGO
}

In a former paper on the subject of leukoplakia of the urinary organs, $I^{1}$ reported a case of leukoplakia of the bladder and lower end of the ureter. At that time, a careful review of the literature was made and a brief summary was given of the histories of forty-four cases that I was able to find in the literature at my command, making a total of forty-five cases.

During the past year, two publications have appeared in which two new cases were reported, one by Richey ${ }^{2}$ of Pittsburgh and one by Marion ${ }^{3}$ of Paris. Richey's case occurred in the kidney pelvis; and, in Marion's case, the bladder was the seat of this unusual change. Marion's case also showed the presence of epitheliomatous degeneration.

Several years ago, Pollack ${ }^{4}$ reported a case of leukoplakia of the kidney and one of the bladder which were not included in my previous paper. These two reports, with the two cited and two cases about to be reported, make a total of fifty-one cases.

In my former paper the following conclusions were drawn:

1. Leukoplakia is a rare condition.

2. The etiology is unknown.

3. The histopathologic findings appear to be uniform and constant.

4. There is no symptom or syndrome by means of which the condition can be diagnosed.

5. The presence of large quantities of squamous epithelial cells in the urine from the bladder and from the kidney after ureteral catheterization, and the passage of pieces of membrane or flakes of squamous epithelial cells are very valuable findings in making the diagnosis.

6. By means of careful cystoscopic examination, leukoplakia of the bladder can be definitely recognized.

The first case of leukoplakia of the kidney pelvis herewith reported came under observation, Sept. 21, 1920 . A nephrectomy was performed for a right-sided renal tuberculosis. The presence of leukoplakia was not discovered until after the removed kidney was cut open and the pelvis exposed.

1. Kretschmer, H. L.: Surg., Gynec. \& Obst. 31:325 (Oct.) 1920.

2. Richey, DeW. G.: J. Lab. \& Clin. Med. 5:635 (July) 1920.

3. Marion, G.: J. d'urol. 9:257, 1920.

4. Pollack: Beiträge zur Metaplasiefrage, Wiesbaden, 1901 ; Ueber Knochenbildung in der Lunge, Virchows Arch. f. path. Anat. 165: No. 1. 


\section{REPCRT OF CASES}

CASE 1.-History.-Mrs. G., aged 40, three years before coming under observation was operated on because of bladder distress. A tumor was removed from the right ovary and half of the left ovary was removed. The symptoms were not relieved by this operation.

Three weeks ago the patient was subjected to cystoscopic examination elsewhere, and a diagnosis of multiple ulcers of the bladder was made. The onset occurred about four years ago, with practically constant symptoms. Following the operation there was some relief of symptoms for about two months. The patient voided about every hour during the day and five or six times in the early part of the night, and then at longer intervals as the night progressed. The pain was located in the bladder and was present during and after urination, being worse when the bladder was full. It was aggravated when the patient was on her feet and was relieved by rest and alkaline treatment. Urgency had been present ever since the onset of trouble. If the patient did not have the opportunity to void immediately on having the desire, the urine escaped. This was because the pain in the bladder became so intense that she seemed to lose control. Shortly before operation, the patient noticed clots of blood in the urine; but no blood was ever seen until about two months ago, when the urine was red and contained clots. Tenesmus has been present since the onset of symptoms. Long shreds of fleshlike material were occasionally seen in the urine.

Results of Urine Examination

\begin{tabular}{|c|c|c|c|c|}
\hline & Cell Count & Cultures & Urea & Tubercle Bacilli \\
\hline Bladder....... & 70 cells & Staphylococci & 0.25 & Positive \\
\hline Right kidney... & 520 cells & Sterile & 0.4 & Positive \\
\hline Left kidney.... & Red blood cells & Sterile & 0.45 & Negative \\
\hline
\end{tabular}

Examination.-Roentgen-ray examination was negative for stone in the kidneys, ureters and bladder. Cystoscopic examination, Sept. 23, 1920, revealed a bladder capacity of 2 ounces $(59.2$ c.c.). Cystoscopy was very painful. Near the air bubble was seen an area of superficial ulceration surrounded by a zone of hyperemia. Adhering to the surface of the ulcer was a shred. On the posterior wall, a similar ulcer was seen. The ulcers were about half the size of a finger nail. The right ureteral orifice was slightly edematous; and a great deal of difficulty was experienced in passing the catheter up the right ureter. Five catheters were used and all stopped $1 \mathrm{~cm}$. up. Finally a small No. 4 catheter was passed. Urine from the left side was clear; but in the urine from the right side there were a few specks.

Operation.-Dec. 9, 1920, under ether anesthesia, the usual right lumbar nephrectomy was performed. The patient made an uneventful recovery.

Description of Gross Specimen.-The kidney was about normal in size and color. The capsule stripped easily, leaving a smooth regular surface, with the exception of two areas. One area, about $2 \mathrm{~cm}$. in diameter, on the posterior superior aspect of the kidney, was very slightly sunken. It was. of a darker color. On close observation, small yellowish or grayish tubercles, the size of a pinhead, could be seen. There was a similar area, $1 \mathrm{~cm}$. in diameter, on the medial surface. Sections of these areas showed the cortical markings to be destroyed and the process to extend in a wedge-shaped mass down to 
the calices. In it were a number of gray or yellowish hard tubercles, the size of a pinhead, from which tubercle bacilli were obtained on direct smear. The calices involved had lost their normal, smooth, glistening appearance, were very irregular and contained yellowish white elevations, varying in size from that of a pea to that of a pinhead. Otherwise the cortex and medulla appeared to be normal.

The upper part of the pelvis was normal and had a grayish white glistening appearance (Fig. 1). On the lower part, about the ureteral outlet there was an area measuring $2 \mathrm{~cm}$. by $1.5 \mathrm{~cm}$., extending down the ureter for $1.5 \mathrm{~cm}$., very sharply demarcated from the rest. It was of a slate or bluish-gray color, becoming purplish down the ureter, where it abruptly ceased and normal ureteral lining began. The borders were sharply outlined but very slightly elevated. The surface was rough, thrown into irregular folds, and on it were collections of cells resembling cholesteatomas. The ureter was not thickened or hardened.

CASE 2.-History.-L. B., a man, aged 26, entered the United States Veterans' Hospital No. 76, complaining of pain in the bladder region, hematuria, frequency, urgency, tenesmus and pain in the right side of the abdomen in the region of the right kidney. The present illness began in 1918, following an attack of influenza while in service in France. At this time, some clots of blood were noticed in the urine, this condition lasting for several days. At the time of admission to the hospital, bright red blood was present at the end of urination. Pain in the right side of the abdomen was of a dull aching character and generally it was relieved by taking a cathartic. These attacks of pain occurred once or twice a month and lasted for three or four days.

Examination.-Physical examination was negative. Roentgenograms showed the right kidney outline low and apparently very much larger than normal. The outline of the upper pole was not seen in the roentgenogram. No stone shadows were present. Cystoscopic examination revealed no signs of stones or tumor. Near the apex of the bladder was an area of ulceration surrounded by a zone of hyperemia. The surface of the ulcer was covered by a slough. There was a second similarly shaped ulcer behind the right ureteral orifice. Ureteral orifices were normal and were easily catheterized. Specimens of urine obtained from the right and left catheters were sterile on culture. A few pus cells were noted in the urine from the left kidney. Examinations of the urine for tubercle bacilli were negative. The phenolsulphonephthalein test showed an output of 41 per cent. from the right kidney in two hours and 36 per cent. from the left kidney. A pyelogram revealed the presence of a large hydronephrosis on the right side.

Operation.-Feb. 25, 1922, the usual oblique lumbar incision was made over the right kidney area. Delivery of the kidney was difficult because of the short pedicle and the large size of the hydronephrotic kidney. The pelvis was isolated; the ureter was divided at the pelvic brim and the kidney was removed.

Postoperative Course.-Ten days after operation the patient developed phlebitis of the left leg.

Description of Gross Specimen.-The specimen consisted of a large hydronephrotic kidney, about 7 inches $(17.8 \mathrm{~cm}$.) long, the surface of which was irregular. The pelvis was $23 / 4$ inches $(7 \mathrm{~cm}$.) wide and $31 / 2$ inches $(8.9 \mathrm{~cm}$.) long. The ureter and pelvis of the kidney were opened; the mucosa was normal. In the posterior wall of the kidney pelvis was seen an area two-thirds inch $(17 \mathrm{~mm}$.) long and one-fourth inch $(6.4 \mathrm{~mm}$.) wide which stood out in marked contrast to the rest of the kidney pelvis. It was dull white and presented a 


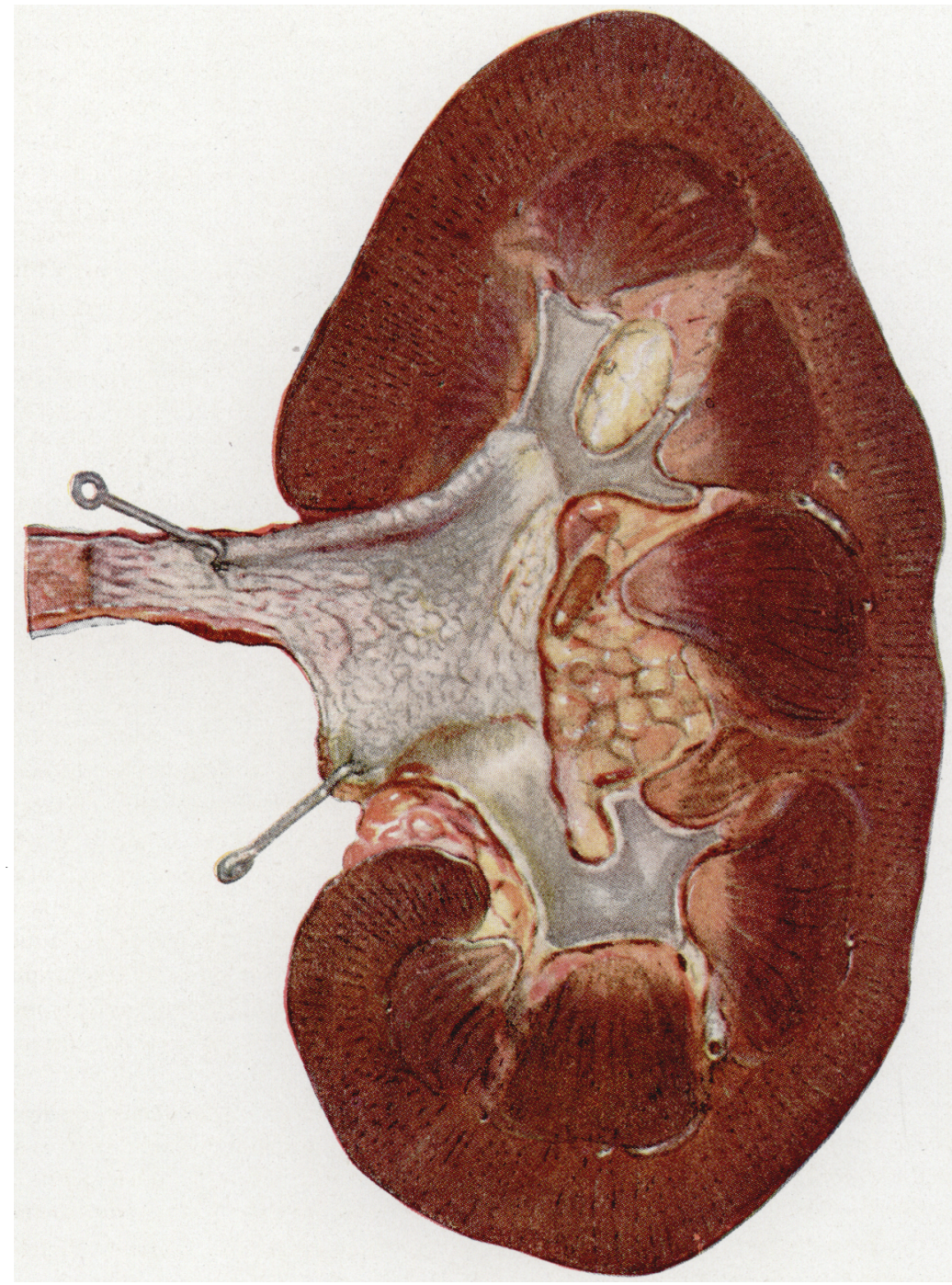

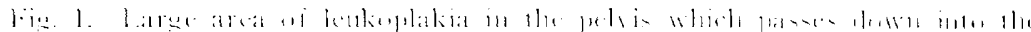

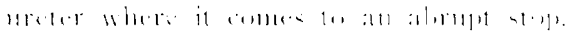


dry, lusterless appearance. The gross appearance was that of leukoplakia. The rest of the kidney showed an enormous amount of dilatation. A small piece was excised for histologic study. Examination demonstrated stratified squamous epithelial cells. This area of metaplasia occupied the posterior wall of the pelvis and was situated $11 / 4$ inches $(3.17 \mathrm{~cm}$.) above the ureteral opening.

\section{COM MENT}

Metaplasia is the postnatal production of specialized tissues from cells which normally produce other kinds of tissues and is an adaptation, on the part of the cells, to an altered environment (Adami and McCrae ${ }^{5}$ ). It may occur either as a physiologic or a pathologic process. I am of the opinion that we are inclined to forget that metaplasia occurs as a physiologic process. As an example of this type of metaplasia may be mentioned the conversion of cartilage into bone, as well as the conversion of connective tissue corpuscles into fat cells. An important point to remember is that epithelial tissue can be transformed only into epithelial tissue and mesoblastic tissue only into other forms of mesoblastic tissue.

Heterotopia should not be confused with metaplasia, the former consisting of the abnormal snaring-off of cells of an organ from the organ proper and its subsequent growth in another place. Two forms of heterotopia are generally recognized-congenital and acquired. Aberrant suprarenals and accessory spleens may be mentioned as congenital types, and bony growths from displaced periosteum as examples of the acquired types. Therefore, in heterotopia there is no transformation of tissue.

Likewise, metaplasia should be differentiated from heteroplasia, which, according to Adami and McCrae, is the condition in which we find, in the middle of the esophagus, normally lined by squamous epithelium, islands of columnar epithelium, similar to epithelium in the stomach. No conversion has occurred from one type of epithelium into the other; there is merely a persistence of misplaced tissue.

Another condition which lies outside the discussion is the growth of one tissue to push back the normal tissue and to replace it. According to McCallum, this occurs, for example, when the skin about a healing tracheotomy wound grows through the opening and extends inward, so as to line the trachea for a short distance. I once saw this occur in the urinary bladder in which a suprapubic fistula had been present for several years.

Many are the views that have been advanced from time to time to explain the occurrence of metaplasia; but the real etiology of this condition is unknown. The presence of calculi in the bladder in a

5. Adami, J. G., and McCrae, John: Textloook of Pathology, Philadelphia, Lea \& Febiger, 1912, p. 202. 
few of these cases has led a number of authors to believe that stone may be a factor in the causation of the condition, despite the fact that stone is not always found in these cases. Again, there are innumerable cases of bladder stone which have never shown the presence of leukoplakia. The idea advanced is that a stone or foreign body produces irritation and that irritation in turn results in leukoplakia. Attention has also been directed to similar plaques in the mouth that are often encountered in pipe smokers; and it is believed that they, too, are due to irritation.

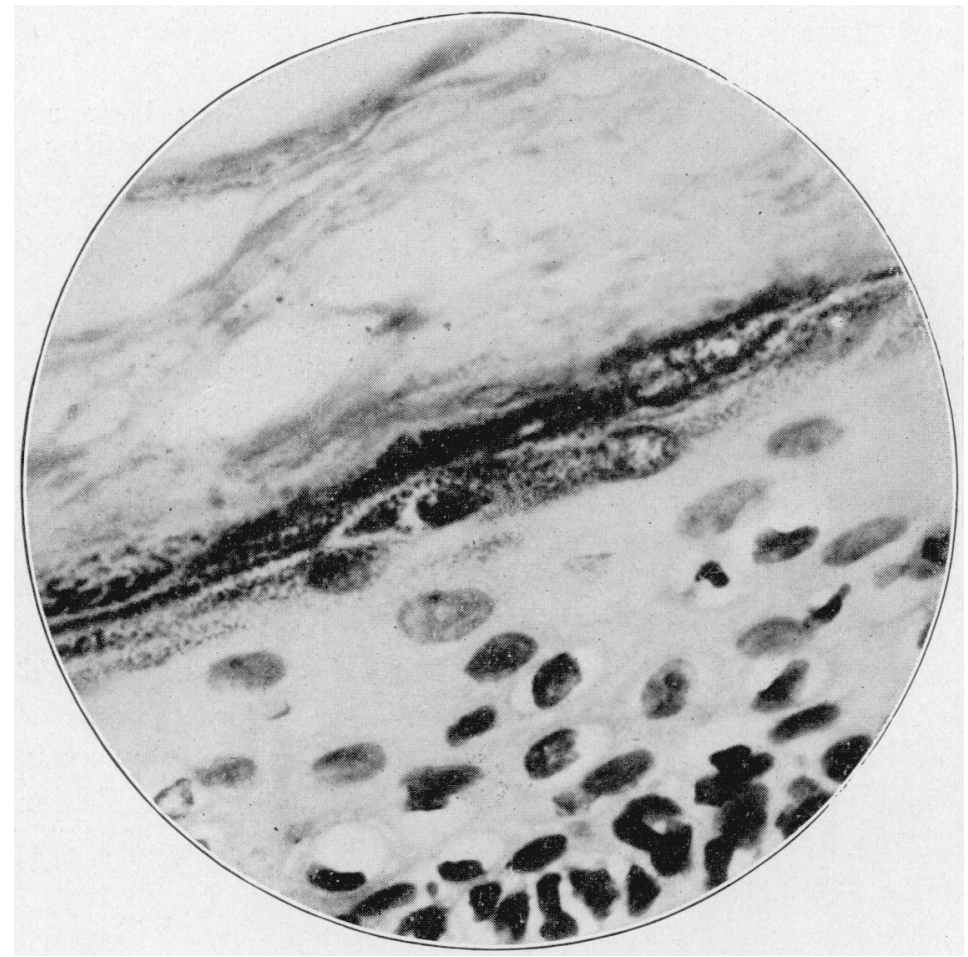

Fig. 2.-Large amounts of desquamated squamous ceils adhering to the surface of the mucosa of the pelvis of the kidney; the submucosa showing round cell infiltration.

Lecène is not inclined to believe that chronic inflammaticn is responsible for this condition. He thinks that the lesion is congenital, owing to disturbances in the development of the urinary apparatus. He states that embryologically it is easy to explain heterotopia of the ectodermic cells in the vicinity of the mucosa of the upper urinary passages; and the fact that this may occur is sufficient to account for the lesions of leukoplakia. 
Hallè asserts that chronic inflammation, simple or calculous, may produce an epithelial transformation in the mucosa of the urinary tract, the normal covering being transformed into stratified pavement epithelium with epidermic characteristics.

The same authority in reporting his cases states that study shows the influence of chronic inflammation in the etiology of epithelial transformations, for, with few exceptions, these patients have an old cystitis, or a ureteropyelitis and cystitis due to gonorrhea, stricture or

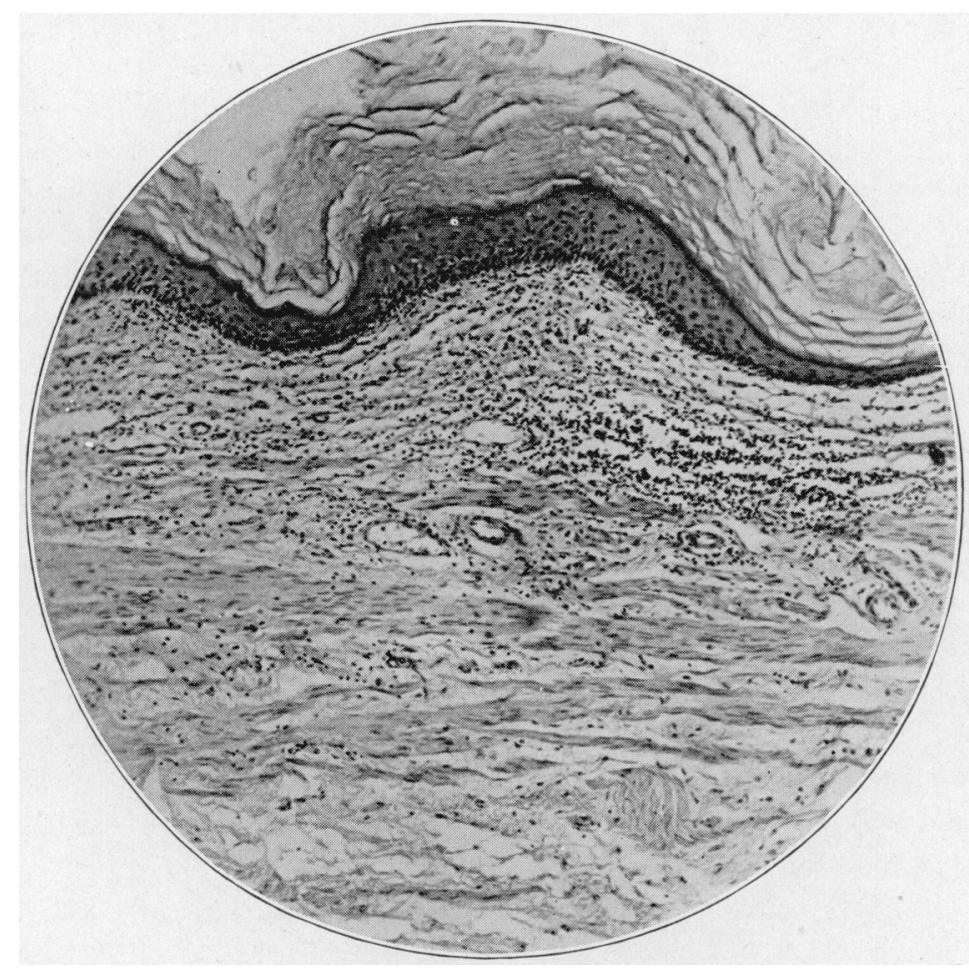

Fig. 3.-Stratum granulostm above which are seen the lamellae of desquamated squamous cells.

prosta:ic disease, or a postpuerperal cystitis due to catheterization, especially in cases in which the condition has been tenacious, and rebellious of treatment.

Lichtenstern mentions as etiologic factors, long-continued inflammation, foreign bodies, stones, tuberculosis, etc.

Posadas believes that leukoplakia, in most instances, offers a pathologic condition, the origin of which may be traced back to syphilis; and when this is found, the benefit from specific treatment is unquestionable. He is of the opinion that if we do not obtain satisfactory results with the usual methods of treatment when it is a matter of 
a decided vesical affection with febrile hematuria and the throwing off of purulent mucosa, we should try mercurial treatment before proceeding to suprapubic cystotomy.

That leukoplakia of the kidney pelvis may have a congenital origin has been mentioned; and to illustrate this fact, the case of Leber has been repeatedly cited. Leber's case, it will be recalled, occurred in an infant, 4 months old, in whom, besides leukoplakia of the kidney, there was also leukoplakia of the eye.

Wells ${ }^{6}$ states that in metaplasia we have what may be interpreted as a chemical alteration due to mechanical stimuli, that is, the formation of keratin by cells which ordinarily do not form it.

Cases of metaplasia occurring outside the urinary tract have been reported by various observers. Haythorn ${ }^{7}$ has reported a case of primary carcinoma of the lung, arising in a bronchus. The lower layer of cells remained columnar in type, while the more superficial layers were composed of typical stratified squamous cells. A case of stratified squamous-cell carcinoma of the lung with cornification was reported by Cohn. ${ }^{8}$ Typical pearls were formed in sections of this tumor.

In discussing the question of metaplasia, Lewisohn ${ }^{9}$ reported two cases of unusual carcinoma, one of the uterus and one of the pancreas. He considers the question as to whether there is a real metaplasia of epithelium, and says: "It is conceivable that a typical pavement epithelium cancer of the uterus might originate without such a metaplasia, since it is not far from the pavement epithelium of the portio vaginalis; hence there might be a displacement, or even an extension of this pavement epitheitum to the uterus. But this explanation will hardly hold in the case of tumor of the pancreas, since the pancreas does not lie near any tissue of ectodermal origin."

Cases in which metaplasia occurred in the epididymis have also recently been reported by Cunningham and Ohmori.

\section{ASSOCIATED KIDNEY PATHOLOGY}

Various associated pathologic conditions have been found in the kidneys. In one case described in this paper, there was an early renal tuberculosis with tuberculosis of the bladder. Tuberculosis of the kidney was also found in Beer's case, as well as in the case reported by Beselin. In my second case there was a large hydronephrosis.

Renal calculus with letkoplakia has been reported by Hallè, Chiari, Pollack $^{4}$ (Lubarsch's case); and in Ronas' case, there were stones in the pelvis and ureter of the opposite side.

6. Wells, H. G.: Chemical Pathology, Philadelphia, W. B. Saunders Company, 1918, p. 285.

7. Haythorn: J. M. Research 26:523, 1912.

8. Cohn, quoted by Lewisohn: Ztschr. f. Krehsforsch. 3:528, 1903.

9. Lewisohn: Ztschr. f. Krebsforsch. 3:528, 1903. 
In Lecène's case, there was a large infected kidney with retention. One of Ronas' patients had a purulent perinephritis; and in Brik's case, there was an associated interstitial nephritis.

\section{DISTRIBUTION}

From a review of these cases it would appear that in leukoplakia involving the urinary organs, the bladder is most frequently affected. This is evidenced by the fact that in thirty of the reported cases, the bladder was the seat of the pathologic condition, and that in only twelve cases were the kidneys found to have this lesion. In three cases, the ureter was affected.

Various combinations of distribution are also to be noted: bladder, one kidney and one ureter, 1 case; bladder, one kidney and both ureters, 1 case; bladder, two kidneys and two ureters, 1 case; urinary tract, 1 case; one kidney and one ureter, 1 case, and bladder and ureter, 1 case.

\section{RELATIONSHIP TO CARCINOMA}

The entire subject of metaplasia and leukoplakia is interesting from three points of view: (1) as to the various theories that have been advanced from time to time regarding the exact method of origin; (2) as regards the various etiologic factors which supposedly produce or aid in producing this condition, and (3) - not the leastthe relationship that exists between leukoplakia and carcinoma, a possibility that has been repeatedly pointed out in cases of carcinoma of the mouth developing from these plaques.

The presence of stratified squamous cell carcinoma occurring in organs which normally do not contain this type of epithelium is generally explained on the basis of metaplasia of the normal epithelium of these organs into stratified squamous epithelium and the formation of leukoplakia, with subsequent carcinomatous degeneration of these patches or plaques.

To conclude, it may be stated, with a considerable degree of probability, that stratified squamous-cell carcinoma of the kidney and bladder can be explained on the basis of metaplasia with leukoplakia formation.

122 South Michigan Avenue. 